\title{
On the Parental Origin of Trisomy 21 Down's Syndrome
}

Larsson $\mathrm{L}^{1 *}$ and Hulten $\mathrm{MA}^{2}$

${ }^{1}$ Svenska Downforeningen, Linnegatan 75, S-114 60, Stockholm, Sweden

${ }^{2}$ Department of Clinical Genetics, Karolinska University Hospital, Stockholm S-171 75, Sweden

*Corresponding author: Lotta Larsson, Svenska Downforeningen, Linnegatan 75, S-114 60, Stockholm, Sweden, E-mail: ingrid.lotta.larsson@gmail.com

Received date: October 08, 2015, Accepted date: October 17, 2015, Published date: October 26, 2015

Copyright: (C) 2015 Larsson L, et al. This is an open-access article distributed under the terms of the Creative Commons Attribution License, which permits unrestricted use, distribution, and reproduction in any medium, provided the original author and source are credited.

\section{Abstract}

The most common form of Down's syndrome is due to an extra chromosome No. 21, i.e. three instead of two chromosomes 21, Trisomy 21 (T21). This was discovered over 50 years ago. We now know with certainty that the extra chromosome usually comes from the mother (in approximately 19 out of 20 cases) and also that the probability of having a child with Down's syndrome increases with maternal age. However, we still do not know how this comes about.

It is generally accepted that, in rare cases, the mother has carried the extra chromosome 21 since the time when her ovaries were developing, when she herself was a fetus. On the other hand, it is also generally accepted that, in the majority of cases, the extra chromosome is due to an error in the so-called reduction division (meiosis), when the number of chromosomes are halved in the formation of egg cells. The reduction division begins when the mother is a fetus and is not finished until her monthly ovulation, from puberty until menopause.

Maj Hulten, Professor of Clinical Genetics, believe in contrast to most other researchers that many women may be low-grade ovarian T21 mosaics. In other words their ovaries contain both cells with the normal chromosome number as well as those with an extra chromosome, trisomy 21. This in turn could explain both the origin of T21 Down's syndrome in children of younger mothers, and the so-called maternal age effect, i.e. that the probability of having a child with T21 Down's syndrome increases with maternal age.

\section{Interview}

The Swedish Down Syndrome Association has asked Maj Hulten more about the different theories:

If Trisomy 21 in the child is caused by an error in the reduction cell division, how can one explain the so-called "Age Effect", i.e. that the likelihood of having a child with Trisomy 21 Down's syndrome increases with maternal age?

The first part of the reduction division (the so-called Prophase) starts already when the mother herself is a fetus (before the 20th week of pregnancy) and is completed when the chromosome number is halved, just before ovulation of the mother as an adult. The Meiotic Prophase can therefore last for no less than 13-50 years - from the time the mother was a fetus until her menopause.

Very many hypotheses have been put forward to explain damage done to the oocytes during this very long resting period of the Meiotic Prophase, so that they can no longer divide normally just before the ovulation. Suggested causes to this effect range from the accumulation of the toxic effects by for example environmental pollution, viruses, mitochondrial mutations, energy deficiency, protein deficit, hormonal imbalance, reduced fertilization due to decreased sexual activity, and so on [1].

What support is there for the view that Trisomy 21 can occur in the ordinary cell division, in normal body cells?

There are quite a few reasons to believe that inaccurate chromosomal division, so-called Non-Disjunction, can happen in ordinary body cells. For example, there are people, who are known
Trisomy 21 Mosaics, and they have different degrees of mosaicism in different tissues.

But, the important question is if Trisomy 21 might have arisen in the ordinary cell divisions that occur in the immature egg cells, socalled Oogonia, during the fetal development of the mother? To answer this question you have to determine the number of chromosomes 21 in the oogonia of the mother. The oogonia exist in the ovaries of female fetuses from around 5 weeks up until around week 30 of the pregnancy [2].

\section{Do normal oogonia have 46 or 23 chromosomes?}

They have 46 chromosomes.

\section{How do you count the number of chromosomes in fetal ovaries?}

We prepared oogonia from fetal ovaries, obtained from 20 fetuses, where pregnancy had been terminated for social reasons. Chromosome analysis of cultured skin cells showed that these fetuses had normal chromosome sets, i.e. 46, XX. The cell preparations from the fetal ovaries were stained in such a way that each chromosome 21 got two fluorescent labelled markers. We then counted the number of chromosomes 21 in nearly 40.000 oogonia from a total of 20 fetal ovaries [3].

\section{And what did you find?}

Through this manual and time-consuming fluorescence microscopy (FISH), we demonstrated that the frequency of trisomy 21 in the fetal ovarian samples, where the termination of pregnancy occurred early (weeks 9-11), was relatively low, on average 1/1000 cells. However, 
trisomy 21 frequency in the fetal ovarian samples, where the termination of pregnancy occurred later (week 19-22) was higher, on average $1 / 200$ cells. The reason for this increase in the frequency of trisomy 21 oogonia is unknown.

If the proportion of oogonia with T21 increases as the ovaries develop, how does it matter?

It is known from experiments in mice that there is a queue of egg cells in the ovaries of the mother, so that the ones that are entered first are also the ones that are ovulated first: "First In - First Out". So I and my co-workers came to the conclusion that the explanation for the maternal age effect, as regards the likelihood of getting a child with Trisomy 21 Down's syndrome, is due to the degree of pre-meiotic T21 mosaicism, i.e. Trisomy 21 mosaicism that has emerged in the ovaries of the mother when she herself was a fetus [4].

Is there any other support for the view that the maternal age effect might be explained by T21 oocytes being placed far back in the queue since when the mother was a fetus?

Yes, for example, a Hungarian study compared the use of oral contraception between a group of women that had trisomic fetuses (trisomy 21,18 or 13) and a control group of women, whose fetuses did not have any trisomies. It turned out that longer periods of oral contraception use were associated with fewer trisomy fetuses. Thus, if you stop the ovulation cycles, then the queue is halted. It has also been shown that mothers, who have had a child with T21 DS at an early age, themselves have T21 mosaicism in some of their ordinary body tissues [5].

What would it take to get "the pre-meiotic theory" generally accepted?

By analysis of oocytes that have been discarded from in vitro fertilization (IVF) procedures it has already been shown that both numerical and structural chromosome abnormalities may exist in primary/immature oocytes. These abnormalities must have existed already in premeiotic/mitotic oogonia.

One further possibility would be to record the proportion of T21 oocytes in late fetal ovaries, i.e. where pregnancy has been terminated after week 20 of the pregnancy. If we then find a certain percentage of T21, then T21 must have arisen before the entry of the meiotic prophase, i.e. in the pre-meiotic oogonia.

A different approach would be to score the frequency of T21 DS in ordinary body cells of mothers with T21 children, in comparison to mothers of the same age, who have not had a child with T21 DS. This type of analysis could be done with advanced DNA technology. The occurrence of T21 in ordinary body cells is likely to be correlated with the same in pre-meiotic oogonia.

You could also test fathers with T21 children and compare with a control group in the same way. About 5-10\% of children with T21 DS have received the extra chromosome 21 from their father.
If we tested children with T21 Down's syndrome themselves this way, I believe that we would find that a higher proportion of them have T21 mosaicism than has previously been detected $[6,7]$.

Why does it matter whether T21 originates in ordinary cell divisions or during the reduction divisions?

I believe that such knowledge would be very important, above all because many mothers believe that the Trisomy 21 in their child is caused by something they have done themselves, how they have been living, what they have eaten etc.

I also believe that if you can be tested and get your personal likelihood of having a child with Down's syndrome before you get pregnant, then you would have time to learn more about what it means to have a child with this syndrome. I believe that fewer fetuses would then be aborted. A prognosis that you get during an ongoing pregnancy does not at all give you the same possibility to prepare yourself of what it means to have a child with Down's syndrome [8-10].

\section{References}

1. Hultén MA, Jonasson J, Iwarsson E, Uppal P, Vorsanova SG, et al. (2013) Trisomy 21 mosaicism: we may all have a touch of Down syndrome. Cytogenet Genome Res 139: 189-192.

2. Hultén MA, Patel SD, Tankimanova M, Westgren M, Papadogiannakis N, et al. (2008) On the origin of trisomy 21 Down syndrome. Mol Cytogenet $1: 21$.

3. Polani PE, Crolla JA (1991) A test of the production line hypothesis of mammalian oogenesis. Hum Genet 88: 64-70.

4. Hultén MA, Patel S, Jonasson J, Iwarsson E (2010) On the origin of the maternal age effect in trisomy 21 Down syndrome: the Oocyte Mosaicism Selection model. Reproduction 139: 1-9.

5. Hultén MA, Öijerstedt L, Iwarsson E, Jonasson J (2014) Maternal Germinal Trisomy 21 in Down Syndrome. J Clin Med 3: 167-175.

6. Daina G, Ramos L, Rius M, Obradors A, Del Rey J, et al. (2014) Nonmeiotic chromosome instability in human immature oocytes. Eur J Hum Genet 22: 202-207.

7. Nagy GR, Gyorffy B, Nagy B, Rigo J Jr (2013) Lower risk for Down syndrome associated with longer oral contraceptive use: a case-control study of women of advanced maternal age presenting for prenatal diagnosis. Contraception 87: 455-458.

8. Frias S, Ramos S, Molina B, del Castillo V, Mayén DG (2002) Detection of mosaicism in lymphocytes of parents of free trisomy 21 offspring. Mutat Res 520: 25-37.

9. Migliore L, Migheli F, Coppedè F (2009) Susceptibility to aneuploidy in young mothers of Down syndrome children. ScientificWorldJournal 9: 1052-1060.

10. Iwarsson E, Kvist U, Hultén MA (2015) Disomy 21 in spermatozoa and the paternal origin of trisomy 21 Down syndrome. Mol Cytogenet 8: 67. 